\title{
Management of Transplant Renal Artery Stenosis
}

\author{
Dheeraj K. Rajan, M.D., F.R.C.P.C., ${ }^{1}$ S. William Stavropoulos, M.D., ${ }^{2}$ \\ and Richard D. Shlansky-Goldberg, M.D. ${ }^{2}$
}

Transplant renal artery stenosis is the most frequent vascular complication of transplantation. Early detection and correction reduce patients' morbidity and allograft dysfunction. Although noninvasive imaging can detect an underlying stenosis, angiography with subsequent angioplasty or stenting, or both, provides definitive diagnosis and treatment. With the introduction of alternative contrast agents and newer catheter and stent technology, these procedures can be performed safely with little risk of contrastinduced nephropathy or allograft loss.

KEYWORDS: Kidney transplantation, balloon angioplasty, stents, renal artery stenosis, hypertension, angiography

Objectives: Upon completion of this article, the reader should be able to (1) outline imaging methods for identifying transplant renal artery stenosis (TRAS), (2) list alternative contrast agents or medications to prevent contrast-induced nephropathy, and (3) list methods for management of TRAS, particularly percutaneous interventions.

Accreditation: Tufts University School of Medicine (TUSM) is accredited by the Accreditation Council for Continuing Medical Education to provide continuing medical education for physicians.

Credit: TUSM designates this educational activity for a maximum of 1 Category 1 credit toward the AMA Physicians Recognition Award. Each physician should claim only those credits that he/she actually spent in the activity.

Renal transplantation is the definitive therapy for end-stage renal disease and has especially flourished in the post-cyclosporine-mediated immunosuppression era. Rarely, renal autotransplantation is performed for other reasons, such as for trauma resulting in bilateral renal artery thrombosis. ${ }^{1}$ Historically, angiography has been performed for the evaluation for allograft rejection, delineating donor anatomy prior to surgery, and investigating the etiology of declining renal function after transplantation. At present, noninvasive imaging performed with ultrasonography and nuclear medicine in addition to renal biopsy has supplanted the routine use of potentially nephrotoxic contrast angiography for most renal transplantation evaluations. Newer modalities such as magnetic resonance angiography (MRA) and computed tomographic angiography in addition to carbon dioxide $\left(\mathrm{CO}_{2}\right)$ digital subtraction angiography are now used routinely as well. Transplant renal artery stenosis (TRAS) is the most frequent vascular complication in renal transplantation with an incidence varying between 1 and $25 \% .^{2-6}$ The etiology and management of TRAS vary by location relative to the anastomosis, and it is

Transplant Interventions; Editor in Chief, Peter R. Mueller, M.D.; Guest Editor, Ravi Murthy, M.D. Seminars in Interventional Radiology, volume 21, number 4, 2004. Address for correspondence and reprint requests: Dheeraj Rajan, M.D., F.R.C.P.C., Division of Vascular and Interventional Radiology, Toronto General Hospital, University Health Network-University of Toronto, 585 University Avenue, NCSB 1C-553, Toronto, Ontario, Canada M5G 2N2. ${ }^{1}$ Division of Vascular and Interventional Radiology, University of Toronto, Toronto General Hospital, University Health Network, Toronto, Ontario, Canada; ${ }^{2}$ Section of Vascular and Interventional Radiology, Department of Radiology, University of Pennsylvania, Hospital of the University of Pennsylvania, Philadelphia, Pennsylvania. Copyright (C) 2004 by Thieme Medical Publishers, Inc., 333 Seventh Avenue, New York, NY 10001, USA. Tel: +1(212) 584-4662. 0739-9529,p;2004,21,04,259,269,ftx,en;sir00265x. 
therefore classified relative to this structure. TRAS can occur proximal to the anastomosis (preanastomotic), at the anastomosis, or within the donor artery (postanastomotic). TRAS may be a consequence of faulty surgical techniques, arterial damage during donor nephrectomy or kidney perfusion, kinking and compression of the renal artery, size discrepancy between donor and recipient renal arteries, and chronic rejection. ${ }^{5,7,8}$

\section{CLINICAL PRESENTATION}

Patients can present early or late in the post-transplantation period. They may present with poorly controlled hypertension, compromised function of the allograft, or rejection refractory to immunotherapy. Occasionally, a bruit in the iliac fossa can be heard; this finding is not specific. Although it is the most common long-term complication of renal transplantation, TRAS is the etiology of elevated blood pressure in only 3 to $12 \%$ of the hypertensive patients. ${ }^{9,10}$ Hypertension may occur suddenly or may have a more insidious onset. It is typified by refractoriness to multiple drug regimens. Progressive renal insufficiency may manifest itself and be exacerbated by excess diuresis or occur after use of angiotensin-converting enzyme (ACE) inhibitors. ACE inhibitors may cause a more rapid decline in renal function that may lead to profound hypertension and acute renal failure. ${ }^{11} \mathrm{~A}$ higher incidence of TRAS in transplants from cadavers (13.2-17.7\%) compared with live donors (1.3-5.8\%) has been reported. ${ }^{6,12}$ The interval between transplantation and diagnosis of TRAS ranges from 2 to 45 months. ${ }^{5,13}$ Acute rejection does not appear to correlate with the development of stenosis. $^{5}$

\section{ETIOLOGY}

Mechanical or technical mechanisms of TRAS include atherosclerosis of the donor renal arteries or recipient iliac arteries, or both. In addition, trauma to the vessels during harvesting and transplantation, clamp injury, cannulation for organ perfusion, excess traction on the vessels, and suture techniques are other potential causes. Small subintimal flaps or dissections are thought to occur, leading to intimal scarring and hyperplasia and eventual anastomotic stenosis. ${ }^{14}$ Ostial stenosis is less frequent with a Carrel patch, wherein a cuff of donor aorta is harvested along with the renal artery, used frequently in transplants from cadaver donors.

Nontechnical mechanisms or immunologic causes have been suggested to contribute to TRAS. Intimal proliferation was associated with chronic rejection prior to the introduction of cyclosporine, but no consistent correlation has been found between acute rejection and TRAS. 2,15,16 Cyclosporine has also been suggested as a cause for TRAS by means of inducing endothelial injury leading to the development of a stenosis. ${ }^{17}$ However, no studies have been conclusive.

Early (within a few months of surgery) TRAS is likely to be caused by mechanical or technical trauma, whereas TRAS developing remote (more than 6 months) from the time of transplantation cannot be explained and may be associated with progression of underlying atherosclerotic disease.

\section{RENAL TRANSPLANT SURGICAL TECHNIQUE}

Whether the transplant is from a living related or cadaver donor, the renal artery is anastomosed to the internal iliac artery as an end-to-end anastomosis or to the external iliac artery as an end-to-side anastomosis. ${ }^{18,19}$ The kidney is surgically implanted in either iliac fossa from a retroperitoneal approach through an oblique incision extending from the midline $3-4 \mathrm{~cm}$ from the inguinal ligament to a point just above the anterior superior iliac spine. ${ }^{20}$ When there are multiple vessels in a cadaver donor, a Carrel patch of aorta is used. ${ }^{21}$ With living related donors, multiple renal arteries are a surgical challenge because a patch of aorta containing the additional vessels cannot be obtained. If the additional vessel is small and perfuses only a small segment of kidney, it may be ligated. Larger accessory vessels may be anastomosed end to side to the main renal artery, although this may encroach on the main renal artery lumen. Two or more renal arteries can be anastomosed together side to side to create a "double-barrel anastomosis" preserving the lumen of each vessel. ${ }^{22}$ Other authors have suggested performing separate anastomoses to either the recipient internal or external iliac arteries or one renal branch to each. Another surgical option is to use the recipient's inferior epigastric artery for the accessory vessel. ${ }^{23}$ Pediatric cadaveric donors may have both kidneys with a segment of aorta transplanted en bloc through an anastomosis to the recipient iliac artery. $^{24}$

The renal vein is usually anastomosed to a mobilized recipient iliac vein in an end-to-side fashion. ${ }^{18}$ When two or more renal veins are present, the smaller veins are typically ligated, resulting in a single anastomosis of the larger vein with drainage through an intrarenal venous anastomosis. ${ }^{20}$ When the veins are similar in size, the smaller of the two is first clamped to test for adequate venous collaterals. ${ }^{21}$ When the artery or vein is too short, grafting may be performed, usually with a saphenous vein or occasionally a gonadal vein. ${ }^{25}$ When significant vascular arterial or venous pathology is present, such as inferior vena cava agenesis, unusual surgical anastomoses may be needed. ${ }^{26}$ In children, the renal artery and vein may be anastomosed to the lower aorta and inferior vena cava, respectively. Three types of anastomoses are usually performed to create urinary 
continuity. The most common is the ureteroneocystostomy, which has the lowest incidence of extravasation. More involved transplant surgeries have now been performed in diabetics utilizing both kidney and pancreatic allografts. $^{27,28}$

\section{NONINVASIVE IMAGING EVALUATION}

Evaluation of TRAS may be performed with both noninvasive and invasive imaging techniques. Color flow duplex ultrasound (CFDU) and MRA have now become the primary noninvasive imaging modalities for diagnosing TRAS. CFDU is highly dependent on visualization of the entire donor renal artery and the surgical anastomosis. This imaging modality is also limited by inability to visualize the iliac vessels completely to exclude inflow stenosis at this level, largely because of the patient's body habitus and bowel gas. Stenotic segments appear as regions of focal color aliasing, which with duplex Doppler techniques can be characterized and graded. ${ }^{29}$ Doppler criteria for significant stenosis include (1) peak systolic velocities greater than $2 \mathrm{~m} / \mathrm{sec}$ (Fig. 1), (2) velocity gradient between stenotic and prestenotic segments of more than 2:1, and (3) marked distal turbulence (spectral broadening). ${ }^{30-32}$

Although catheter-based angiography has conventionally been held as the "gold standard" in evaluation of arterial stenosis, three-dimensional gadoliniumenhanced MRA has demonstrated 100\% sensitivity and $75-98 \%$ specificity for greater than $50 \%$ stenosis in small studies. ${ }^{33-37}$ This modality allows evaluation of the iliac arteries, donor artery, arterial anastomosis, and the renal vein (Fig. 2). Both these modalities allow imaging evaluation of the transplant kidney without the use of

A

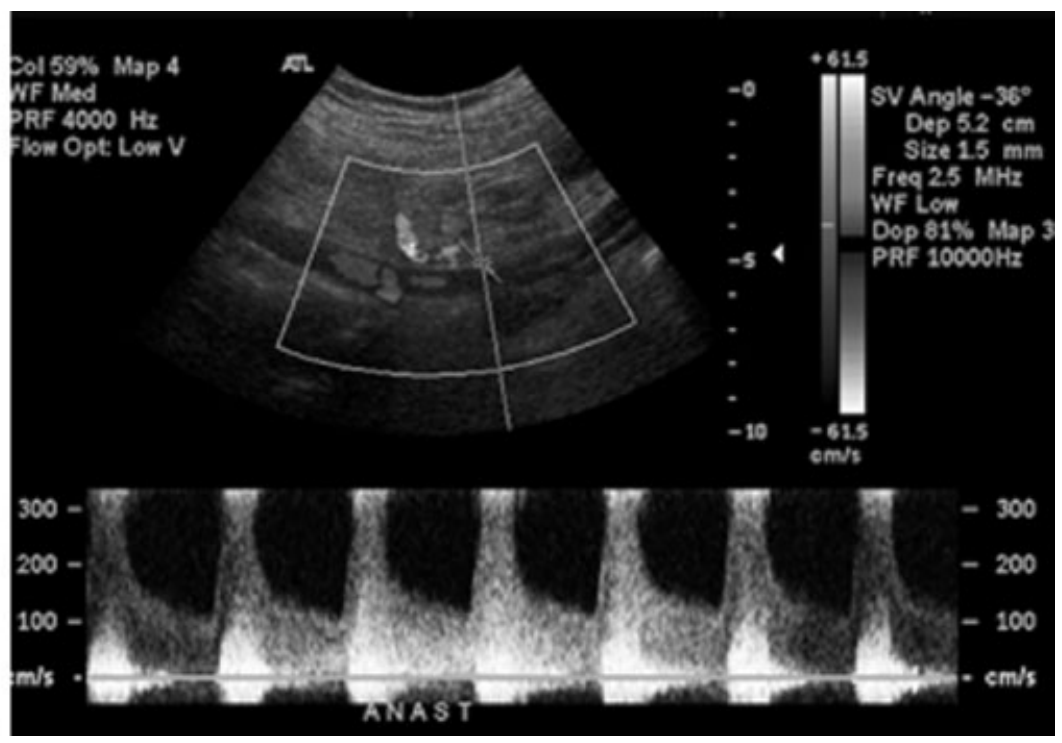

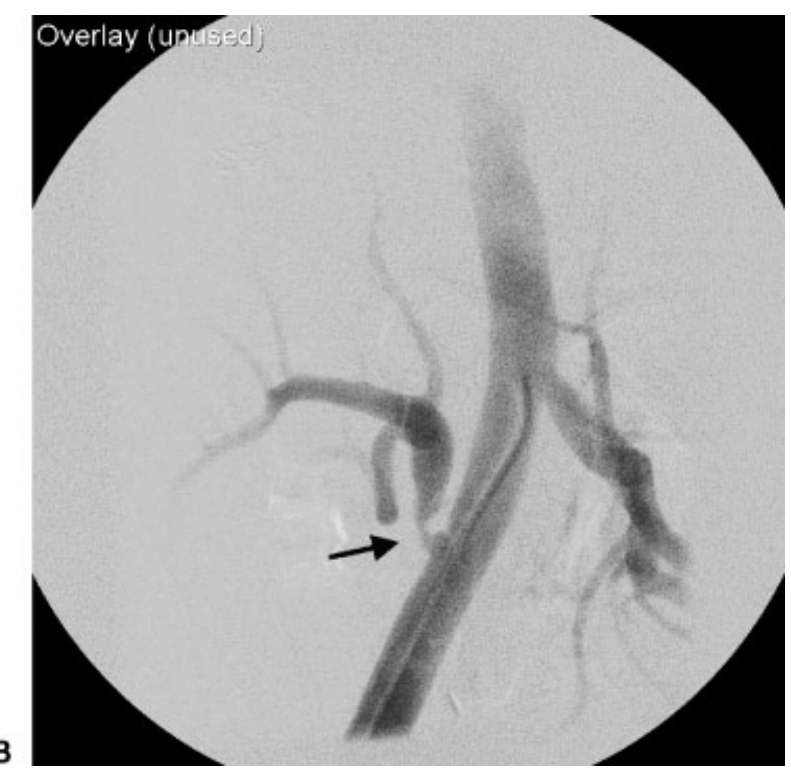

Figure 1 (A) Ultrasound Doppler examination of the renal artery anastomosis to the external iliac artery demonstrated velocities exceeding $3 \mathrm{~m} / \mathrm{sec}$. (B) Selective right external iliac artery angiogram confirms a focal moderately severe and eccentric stenosis at and just distal to the arterial anastomosis (arrow). 


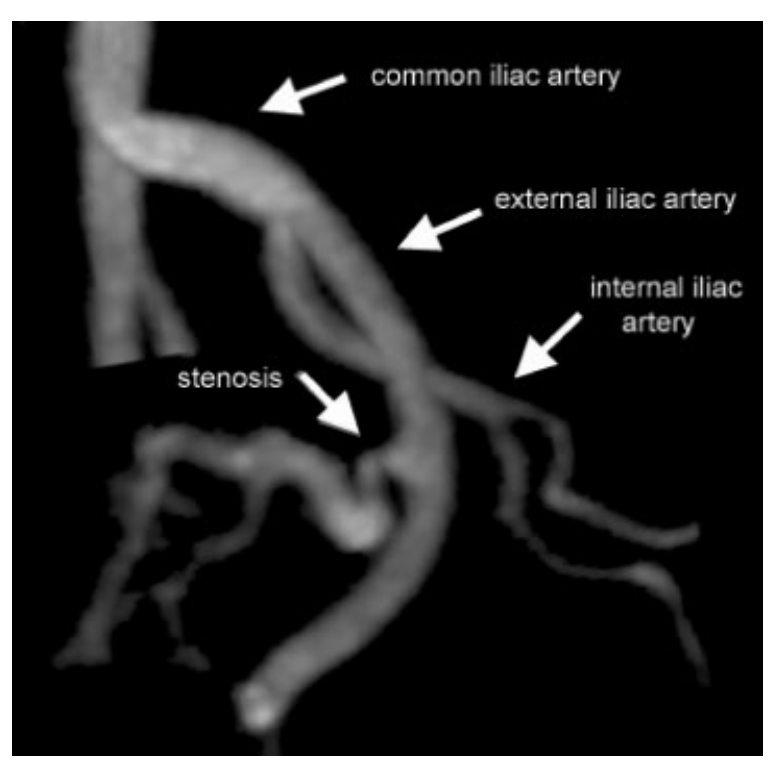

Figure 2 Gadolinium-enhanced three-dimensional MRA reconstructed image demonstrates stenosis of the renal artery distal to the anastomosis. The iliac arteries are completely visualized.

iodinated contrast agents. However, if there is a strong clinical suspicion of TRAS despite negative noninvasive imaging studies, proceeding to angiography should be considered.

\section{RENAL TRANSPLANT ANGIOGRAPHY}

Intra-arterial digital subtraction angiography has now replaced film screen ("cut film") imaging for imaging renal transplants. Because of the risk of nephrotoxicity associated with iodinated contrast media, volume should be carefully tailored to the clinical question with careful consideration of the vascular anatomy, clinical scenario, and possible therapeutic intervention. ${ }^{24}$ Catheter and wire manipulation near the anastomosis or donor transplant renal artery should be kept to a minimum, especially when the transplantation has been recently performed. Consideration should be given to the use of nonionic contrast material because of its possible reduced nephrotoxicity, as its use appears to reduce contrast-induced nephropathy (CIN) by $\sim 50 \% \mathrm{com}^{-}$ pared with high-osmolality agents. ${ }^{38}$ Newer isosmolar contrast media (Visipaque, Amersham Health, Princeton, $\mathrm{NJ}$ ) are considered to have less nephrotoxic effect than nonionic contrast media. 39,40

Ipsilateral or contralateral approaches can be used for donor arteriography when the anastomosis is to the external iliac artery and a contralateral approach when the anastomosis is to the internal iliac artery. A Cobra configuration of catheter works well when performing a contralateral approach. Examination of the distal aorta and common iliac arteries should be performed in hypertensive patients because stenosis related to atherosclerosis or clamp injuries can cause an impediment to inflow, ${ }^{24,41,42}$ leading to local hypoperfusion.

Contrast injection rates depend on the location of the catheter tip and should be guided by fluoroscopic hand injections. Common iliac artery injections are performed at a rate of $7-15 \mathrm{~mL} / \mathrm{sec}$ for a total of 12 $30 \mathrm{~mL}$ and internal iliac artery injections are performed at $5 \mathrm{~mL} / \mathrm{sec}$ for a total of $10 \mathrm{~mL}$, depending on the type of imaging technique utilized. Selective injection into the renal artery is generally not required ${ }^{43}$ if image quality is optimal. Initial films can be obtained in the 30-degree left or right posterior oblique projection for the left- or right-sided transplant, respectively, unless a test injection dictates a different view. Multiple projections such as steep obliques or even a lateral projection are generally required to image the course of the arteries adequately and to visualize the in-profile anastomosis, which is typically placed anterior on the vessel. On average, three views are required to image the transplant adequately, although because of overlap of vessels, as many as six images may be required. ${ }^{44,45}$ The introduction of rotational angiography with three-dimensional reconstruction may allow savings in time, radiation, and contrast dose. ${ }^{46,47}$

The angiographic appearance of a normally functioning transplant is similar to that of a normal native kidney, but its size may vary. A normal transplant may measure up to $16 \times 9 \mathrm{~cm}$, and the size increases $10 \%$ in the first month and $1 \%$ a month for the first year. ${ }^{48,49}$ Complications associated with renal transplant angiography are typical of other similar diagnostic and interventional angiographic procedures. The risk of vascular injury is related to the risk and difficulty of the procedure, and contrast nephrotoxicity is related to underlying impairment of renal function. ${ }^{50,51}$

If the renal transplant is functioning poorly with an elevated creatinine level and contrast angiography is being considered, $\mathrm{CO}_{2}$ angiography may be used to confirm or exclude a diagnosis of a vascular abnormality ${ }^{52}$ (Fig. 3). $\mathrm{CO}_{2}$ acts as a negative contrast agent when combined with intra-arterial digital subtraction angiography and is cleared by the lungs rather than the kidneys. ${ }^{53}$ Current software allows "stacking" of images, producing image quality similar to that obtained with iodinated contrast agents. Because $\mathrm{CO}_{2}$ is not nephrotoxic, it can be used in patients with impaired renal function $^{53-55}$ and has not been shown to change renal function significantly with selective injections. ${ }^{56} \mathrm{CO}_{2}$ works well with renal transplants because the vessels are anteriorly located and the gas rises into the graft, allowing filling of the intraparenchymal arteries. ${ }^{56} \mathrm{~A}$ sufficient volume of $\mathrm{CO}_{2}$ has to be injected to avoid underestimating the diameter of vessels and vessel stenosis, ${ }^{57}$ but the amount that can be injected in subdiaphragmatic arterial vessels should be limited to less than $300 \mathrm{~cm}^{3}{ }^{53}$ The potential for gas trapping or "vapor lock" causing 

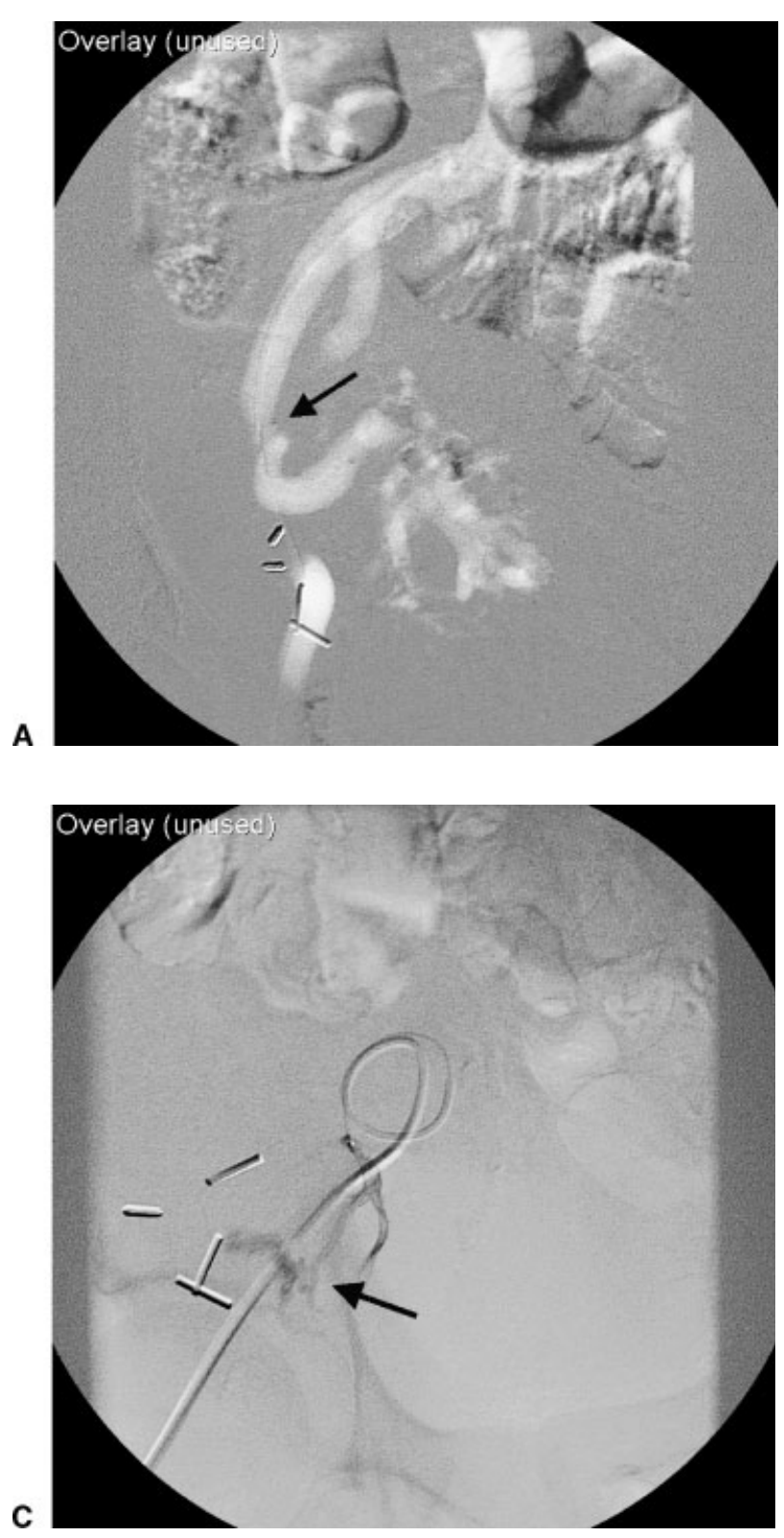

reduced blood flow in the renal artery is eliminated if the minimal volumes for imaging are injected 1-2 minutes apart. ${ }^{52,53}$ Percutaneous interventions can be performed with $\mathrm{CO}_{2}$; however, this is more difficult because image quality may be adversely effected by the hardware introduced during the intervention. When $\mathrm{CO}_{2}$ angiography is inadequate, imaging can be supplemented with gadolinium-based agents. ${ }^{54}$

Gadolinium, a contrast agent primarily administered for contrast-enhanced magnetic resonance imaging, absorbs $\mathrm{x}$-rays similarly to iodinated contrast material. The image quality is inferior to that with iodinated material because of the low concentration of gadolinium $(0.5 \mathrm{mmol} / \mathrm{mL})$ (Fig. 4). Image contrast with gadolinium is typically $25-50 \%$ that of images obtained with traditional full-strength contrast agents. In doses injected for magnetic resonance examinations

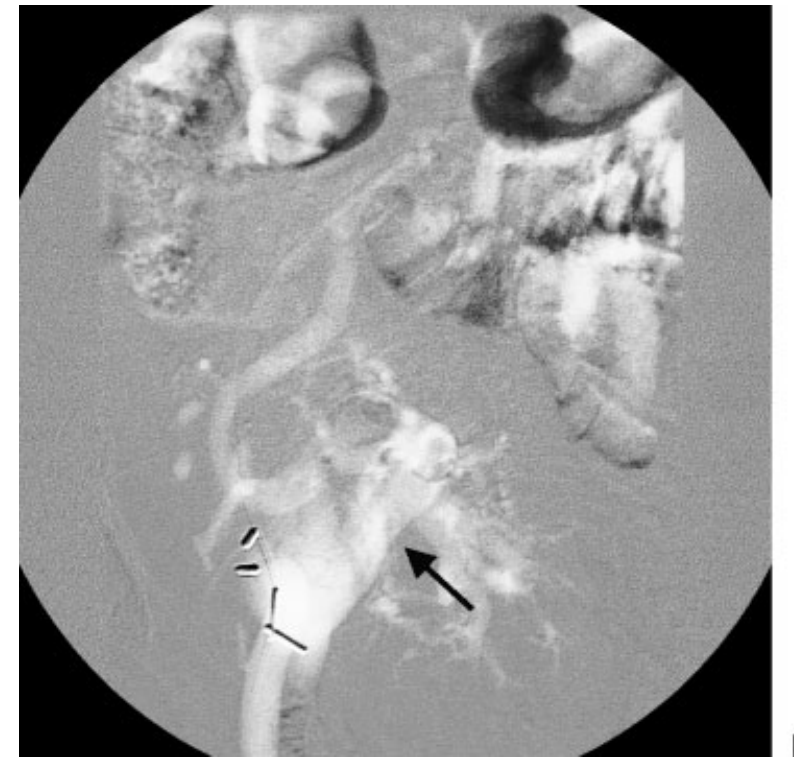

B

Figure 3 (A) Carbon dioxide angiogram of the external iliac artery was performed demonstrating focal stenosis (arrow) of the proximal transplant renal artery as demonstrated in Figure 2. (B) Images obtained 0.2 seconds later demonstrate early opacification of the external iliac vein (arrow). (C) Selective injection of a renal segmental arterial branch verifies an arteriovenous fistula (arrow), later corrected with coil embolization.

(0.1 to $0.4 \mathrm{mmol} / \mathrm{kg}$ body weight) there has been no associated nephrotoxicity in patients with renal insufficiency. ${ }^{58-60}$ However, there has been a report of worsening renal function following a lower extremity angiogram using gadolinium when a dose of $0.44 \mathrm{mmol} /$ $\mathrm{kg}$ was used. ${ }^{61}$ For this reason, we do not exceed a dose of $0.4 \mathrm{mmol} / \mathrm{kg}$ or, as a basic rule, we do not use more than $30 \mathrm{~mL}$ of gadolinium. Gadolinium can be hand or pump injected in a manner similar to injection of iodinated contrast material. It is advantageous to combine gadolinium imaging with $\mathrm{CO}_{2}$ to reduce the amount of gadolinium required for diagnostic images and therapeutic interventions.

Two supplemental medications can be administered to reduce the risk of CIN. Fenoldopam is similar to dopamine, acting on the DA-1 receptor. This medication is a potent renal vasodilator resulting in increased 

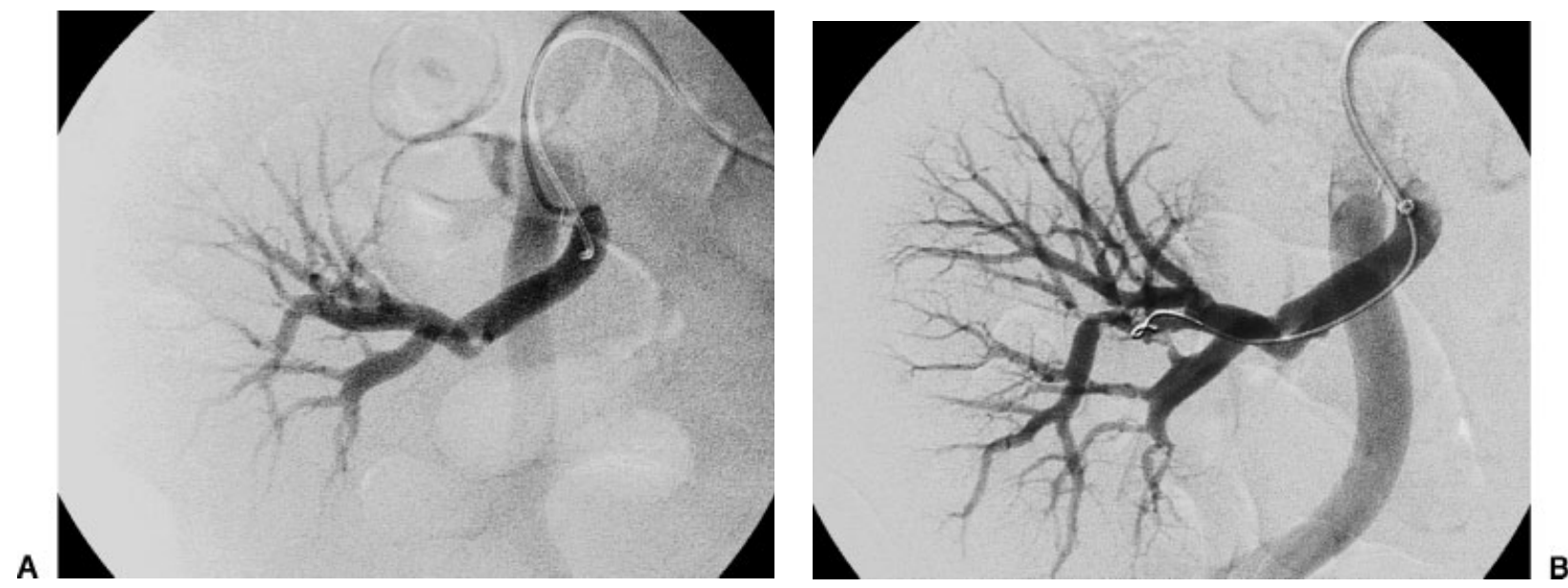

Figure 4 (A) Angiogram performed with gadolinium prior to intervention. (B) Following intervention, an angiogram was performed with a hand injection of iodinated contrast material demonstrating improved contrast resolution compared with gadolinium. The tip of a guiding sheath is visualized in the proximal renal artery.

renal blood flow. ${ }^{62}$ Acetylcysteine, a thiol-containing antioxidant, has been shown to reduce CIN in highrisk patients. ${ }^{63,64}$ Dosing is $600 \mathrm{mg}$ orally twice a day the day before and the day of contrast administration. Although these agents show promise, few studies validating their effectiveness have been published.

\section{MANAGEMENT OF TRANSPLANT RENAL ARTERY STENOSIS}

Three different treatment methods are available:

1. Medical management may be used to control hypertension with unknown effect on kidney function. This approach is indicated if the degree of stenosis is not considered hemodynamically significant or the risk of percutaneous intervention is considered high for graft loss, or both. Intervention is justified if there is a reasonable expectation of success in improving hypertension and renal function or stopping progressive renal deterioration. $8,16,65$

2. Surgical intervention with revascularization. This is considered a major operation with graft loss following vascular reconstruction approaching 30\% with a recurrence rate of $\sim 12 \% .{ }^{65-67}$ There is also an increased risk of ureteral injury with surgery. Surgical correction is the preferred method for treatment of kinking of the proximal transplant renal artery. ${ }^{68}$

3. Percutaneous endovascular management using transluminal angioplasty (PTA) or metallic stent placement, or both.

There are several locations that can develop stenoses. An arterial stenosis may be ${ }^{1}$ preanastomotic, which is usually due to atherosclerosis or a clamp injury $^{18}$; at the anastomosis, which is usually due to a technical problem related to surgery ${ }^{19}$; just distal to the anastomosis, which is usually due to immune reactions or hemodynamic turbulence from the anastomosis causing an intimal hyperplasia ${ }^{20}$; or intrarenal due to chronic rejection. ${ }^{21,24,69}$ Postanastomotic strictures tend to be more severe and associated with end-to-side anastomoses as compared with end-to-end anastomoses, which tend to be at the anastomosis. ${ }^{69,70}$ Iliac artery stenosis ipsilateral and proximal to the renal artery anastomosis can also lead to allograft dysfunction, particularly in the elderly population. . $^{2,71-74}$

PTA is recognized as the initial treatment of choice for TRAS and does not preclude subsequent surgical correction. ${ }^{15,69,75-78}$ However, prior to the introduction of current catheter and wire technology, some investigators had high complication rates up to $20 \%$ with low clinical responses. ${ }^{65,79,80}$ Initial technical success of PTA has been reported to be over $80 \%$ and clinical success is $\sim 74$ to $87 \%$. $^{2,70,75,77,78,81}$ Long-term clinical success, defined as either improvement in blood pressure control or stabilization or improvement in renal function, is between 53 and $70 \%$ at 1 year ${ }^{67,75,77}$ with the restenosis rate of PTA of TRAS to be in the range of 10 to $33 \%{ }^{15,67,75,76,78,79}$ Complication rates are generally low with the rate of graft loss lower for PTA than for surgery; however, Roberts et al reported their loss after PTA to be as high as $13 \%$, higher than their surgical , which may have resulted from dated (1989) angioplasty catheters and wires compared with devices that are available today. ${ }^{16,65,69,70,75,81}$

PTA/stenting of an end-to-side anastomosis can be performed from the contralateral or ipsilateral side, depending on the angle of the anastomosis (Fig. 5). An end-to-end anastomosis, which is generally to the hypogastric artery, is performed from the contralateral side or by a left brachial artery approach. Serious complications, which may lead to graft loss, include acute thrombosis, arterial dissection, renal artery rupture, branch occlusion, 

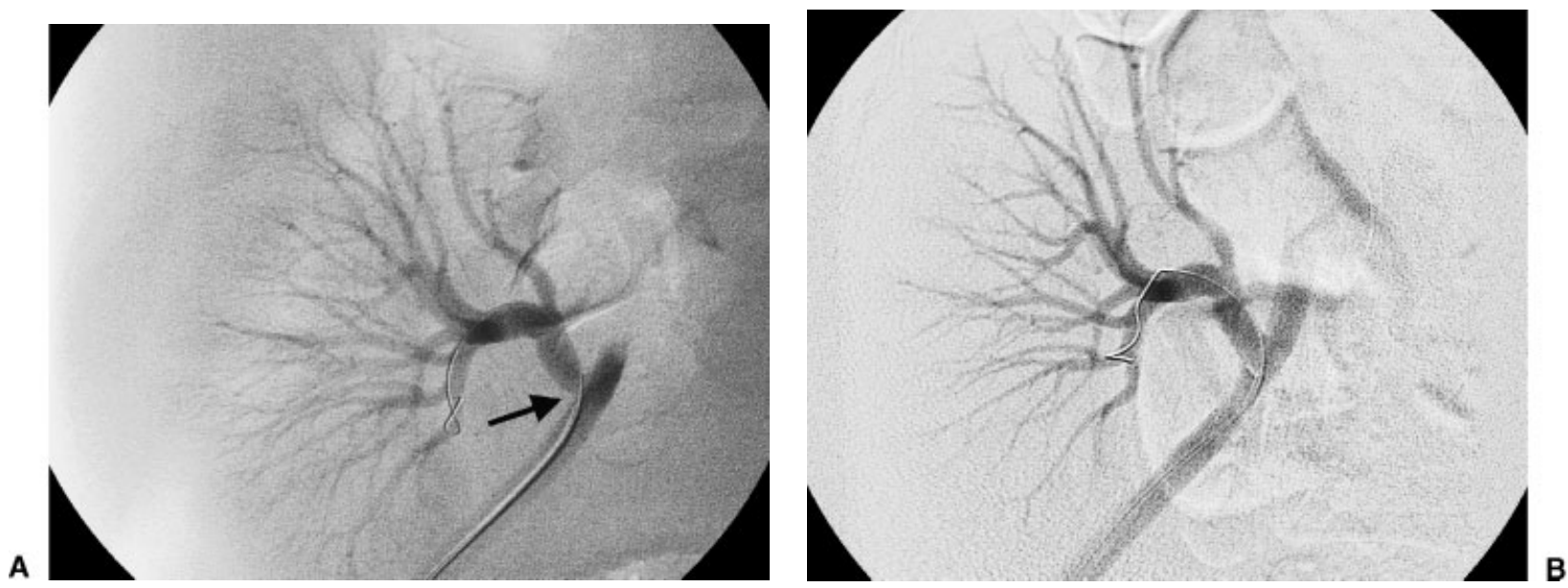

Figure 5 (A) Prior to angiography, ultrasonography demonstrated a velocity of $6 \mathrm{~m} / \mathrm{sec}$ at the external iliac artery-renal artery anastomosis. Gadolinium angiogram confirms stenosis (arrow) in this location. (B) Following angioplasty with an 8-mm balloon catheter, the pressure gradient dropped from $54 \mathrm{~mm} \mathrm{Hg}$ to less than $10 \mathrm{~mm} \mathrm{Hg}$.

distal embolization, and contrast-induced renal failure. As with any renal artery angioplasty, complications are reduced by utilizing adequate heparinization, vasodilators, minimal wire manipulations, proper balloon sizing, and inflation pressures. Because of the potential for a false-positive angiogram, Roberts et al suggested that an angiographic stenosis should demonstrate some physiological significance prior to performing an intervention such as a captopril-associated rise in creatinine or large pressure gradient. ${ }^{65}$

Metallic stents have been inserted for treatment of recurrent or ostial stenosis, although limited studies have been performed to date. Insertion is associated with high initial technical success and a good patency rate with minimal complications. ${ }^{82-84}$ Serious complications of PTA can be salvaged with stents. In addition, elastic recoil can lead to restenosis. Metallic stents are commonly used, primarily to treat ostial stenosis in native renal arteries and now in transplanted kidneys ${ }^{13,82,83}$ (Fig. 6). Complications related to stent insertion include thrombosis, peripheral embolization, transient renal failure, subintimal dissection, stent misplacement or migration, and restenosis related to myointimal hyperplasia from the normal healing process. Newman-Sanders et al reported stable allograft function in four patients with follow-up of 4 to 24 months, ${ }^{83}$ and Nicita et al reported a positive outcome using Palmaz ${ }^{\mathbb{R}}$ stents in five of seven patients at a median follow-up of 14.8 months. ${ }^{13}$ Bertoni et al implanted nine Palmaz ${ }^{\circledR}$ stents for TRAS with no complications with a significant decrease in peak blood flow velocity. ${ }^{82}$

When performing PTA/stenting, we attempt to place the vascular access sheath tip adjacent to the arterial anastomosis (Fig. 4). This allows monitoring

A
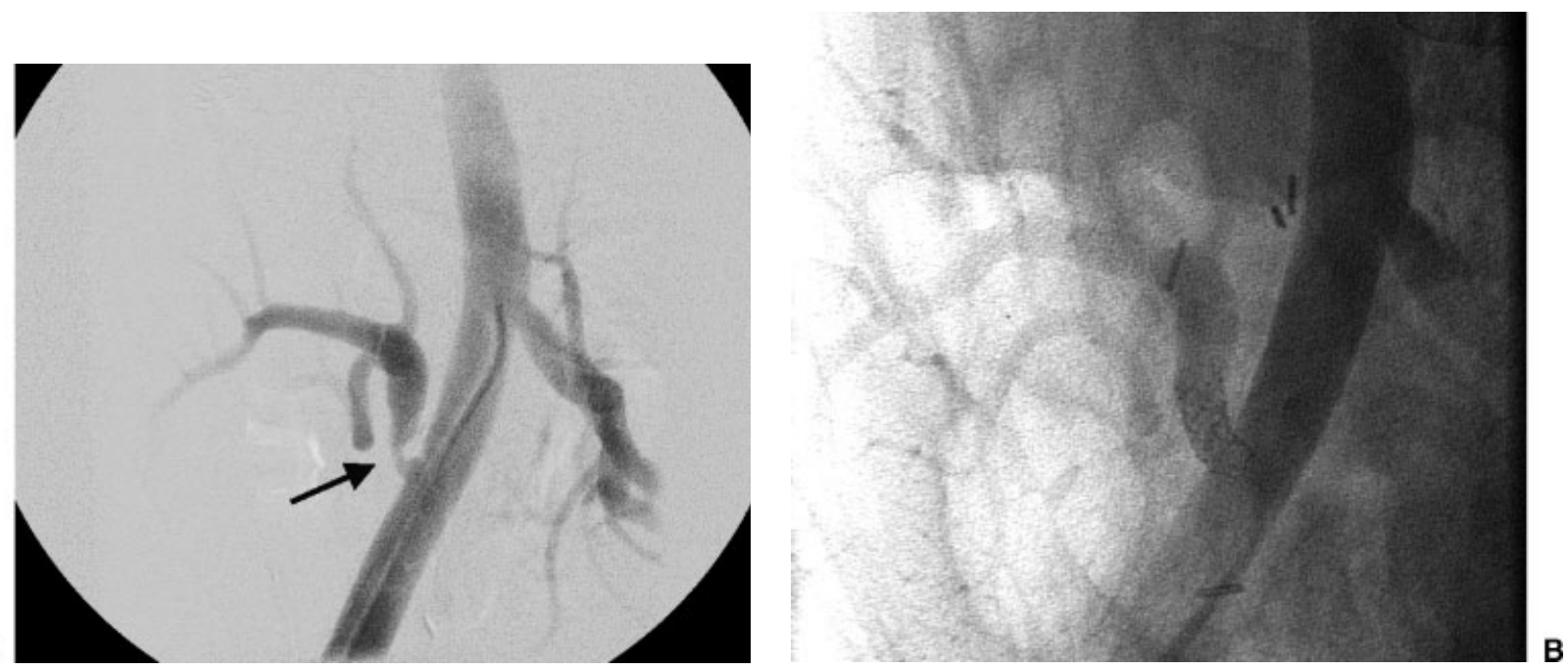

Figure 6 (A) Injection of gadolinium in the external iliac artery demonstrates a focal eccentric stenosis at the anastomosis (arrow) extending into the renal artery. (B) A balloon-expandable stent ( $4.5 \mathrm{~mm} \times 12 \mathrm{~mm}$ length) was primarily deployed and expanded to $4.5 \mathrm{~mm}$. Prior to stenting, the pressure gradient was $77 \mathrm{~mm} \mathrm{Hg}$. Following deployment, the gradient normalized. 
A

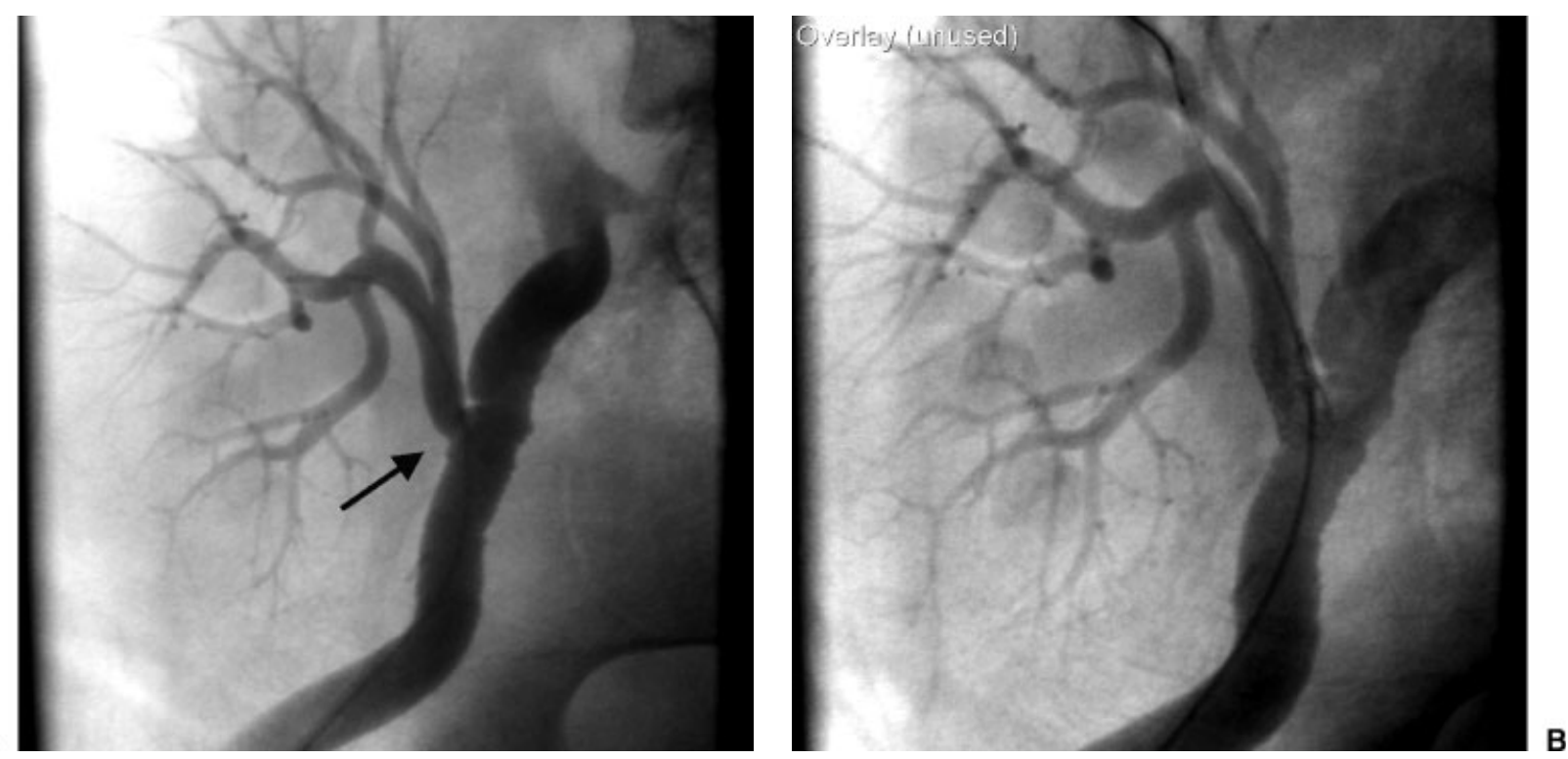

Figure 7 (A) lliac angiogram demonstrates a focal osteal or anastomotic stenosis (arrow) of the transplant renal artery. (B) The lesion was primarily stented with a Palmaz 154 stent dilated to $6 \mathrm{~mm}$. Use of a balloon-expandable stent allowed accurate placement.

the progress of the intervention by angiograms performed with wire access, either a 0.035 or 0.018 access, maintained across the lesion. The vascular sheath can also act as a buttress against a deployed stent to prevent stent migration when removing the deployment balloon. Our indications for PTA include greater than 50\% luminal narrowing with angiography or a systolic pressure gradient of $10 \mathrm{~mm} \mathrm{Hg}$ across the stenotic segment, or both. ${ }^{85}$ Angioplasty balloon and stent sizing may be obtained with the aid of software found on most modern digital subtraction angiography units. Indications for stent use at our institutions include greater than 30\% residual stenosis following PTA, persistent systolic pressure gradient greater than $10 \mathrm{~mm} \mathrm{Hg}$ following angioplasty, flow limiting dissection, and early recurrent clinically significant stenosis within 3 months of angioplasty. We prefer to use balloon-expandable stents for higher radial strength and accurate placement compared with self-expanding stents (Fig. 7). Previous limitations of balloon-expandable stents have now been resolved with the introduction of multiple new stent platforms by a variety of medical device companies; these have a reduced profile and good trackability over the aortic bifurcation and are premounted, preventing migration of the stent off the deployment balloon.

\section{CONCLUSION}

Advances in diagnostic and device technology have allowed improved diagnosis and percutaneous management of TRAS. The use of alternative contrast agents and supplemental medications reduces the likelihood of CIN. Percutaneous transluminal angioplasty with or without intravascular stenting has high technical success with an acceptable complication rate and is the preferred initial therapy in these patients. The introduction of newer technology such as lower profile balloon catheters, premounted balloon-expandable stents, and cutting angioplasty balloon catheters is likely to improve the outcome of percutaneous interventions for TRAS. The success of these interventions requires appropriate selection of patients and attention to meticulous technique.

\section{ABBREVIATIONS}

TRAS transplant renal artery stenosis

PTA percutaneous transluminal angioplasty

CFDU color flow duplex ultrasound

MRA magnetic resonance angiography

$\mathrm{CO}_{2} \quad$ carbon dioxide

CIN contrast-induced nephropathy

\section{REFERENCES}

1. Brunetti DR, Sasaki TM, Friedlander G, et al. Successful renal autotransplantation in a patient with bilateral renal artery thrombosis. Urology 1994;43:235-237

2. Wong W, Fynn SP, Higgins RM, et al. Transplant renal artery stenosis in 77 patients - does it have an immunological cause? Transplantation 1996;61:215-219

3. Chan HW, Ho YW, Chan CM, Yiu TF, Tong MK, Wong $\mathrm{PH}$. Treatment of anastomotic ostial allograft and renal artery 
stenosis with the Palmaz stent. Transplantation 1995;59: 436-439

4. Loubeyre P, Cahen R, Grozel F, et al. Transplant renal artery stenosis. Evaluation of diagnosis with magnetic resonance angiography compared with color duplex sonography and arteriography. Transplantation 1996;62:446-450

5. Sutherland RS, Spees EK, Jones JW, Fink DW. Renal artery stenosis after renal transplantation: the impact of the hypogastric artery anastomosis. J Urol 1993;149:980-985

6. Sankari BR, Geisinger M, Zelch M, Brouhard B, Cunningham R, Novick AC. Post-transplant renal artery stenosis: impact of therapy on long-term kidney function and blood pressure control. J Urol 1996;155:1860-1864

7. Kauffman HM, Sampson D, Fox PS, Doyle TJ, Maddison FE. Prevention of transplant renal artery stenosis. Surgery 1977;81:161-167

8. Tilney NL, Rocha A, Strom TB, Kirkman RL. Renal artery stenosis in transplant patients. Ann Surg 1984;199:454460

9. Smith RB, Cosimi AB, Lordon R, Thompson AL, Ehrlich RM. Diagnosis and management of arterial stenosis causing hypertension after successful renal transplantation. J Urol 1976;115:639-642

10. Munda R, Alexander JW, Miller S, First MR, Fidler JP. Renal allograft artery stenosis. Am J Surg 1977;134:400-403

11. Curtis JJ, Luke RG, Whelchel JD, Diethelm AG, Jones P, Dustan HP. Inhibition of angiotensin-converting enzyme in renal-transplant recipients with hypertension. N Engl J Med 1983;308:377-381

12. Lacombe M. Arterial stenosis complicating renal allotransplantation in man: a study of 38 cases. Ann Surg 1975;181: 283-288

13. Nicita G, Villari D, Marzocco M, Li Marzi V, Trippitelli A, Santoro G. Endoluminal stent placement after percutaneous transluminal angioplasty in the treatment of post-transplant renal artery stenosis. J Urol 1998;159:34-37

14. Smellie WA, Vinik M, Hume DM. Angiographic investigation of hypertension complicating human renal transplantation. Surg Gynecol Obstet 1969;128:963-968

15. Fauchald P, Vatne K, Paulsen D, et al. Long-term clinical results of percutaneous transluminal angioplasty in transplant renal artery stenosis. Nephrol Dial Transplant 1992;7:256259

16. Merkus JW, Huysmans FT, Hoitsma AJ, Buskens FG, Skotnicki SH, Koene RA. Renal allograft artery stenosis: results of medical treatment and intervention. A retrospective analysis. Transpl Int 1993;6:111-115

17. Sawaya B, Provenzano R, Kupin WL, Venkat KK. Cyclosporine-induced renal macroangiopathy. Am J Kidney Dis 1988;12:534-537

18. Hanto DW, Simmons RL. Renal transplantation: clinical considerations. Radiol Clin North Am 1987;25:239-248

19. Flye M. Renal Transplantation. Philadelphia: WB Saunders; 1989

20. Lee H. Surgical techniques in renal transplantation. In: Morris P, ed. Kidney Transplantation Philadelphia: WB Saunders; 1988:215-233

21. Belzer F, Glass N, Sollingerr H. Technical complications after renal transplantation. In: Morris P, ed. Kidney Transplantation Philadelphia: WB Saunders; 1988:511-522

22. Guerra EE, Didone EC, Zanotelli ML, et al. Renal transplants with multiple arteries. Transplant Proc 1992;24: 1868
23. Ganesan KS, Huilgol AK, Sundar S, Chandrashekar V, Prasad S, Raviraj KG. Management of multiple arteries in renal transplantation. Transplant Proc 1994;26:2101-2102

24. Crain M, Ditmanson P, Finlay D. Vascular complications of renal transplantation: angiographic diagnosis and intervention. Semin Interv Radiol 1992;9:235-245

25. Nghiem DD. Spiral gonadal vein graft extension of right renal vein in living renal transplantation. J Urol 1989;142:1525

26. Talbot-Wright $\mathrm{R}$, Carretero $\mathrm{P}$, Alcaraz A, Vilardell J. Complex renal transplant for vascular reasons. Transplant Proc 1992;24:1865-1866

27. Perez R, Navarro MD, del Castillo D, et al. Simultaneous pancreas-kidney transplant compared with kidney transplant in type I diabetic patients with end-stage renal disease. Transplant Proc 2001;33:3494-3495

28. Lo A, Stratta RJ, Hathaway DK, et al. Long-term outcomes in simultaneous kidney-pancreas transplant recipients with portal-enteric versus systemic-bladder drainage. Am J Kidney Dis 2001;38:132-143

29. Tublin ME, Dodd GD III. Sonography of renal transplantation. Radiol Clin North Am 1995;33:447-459

30. Snider JF, Hunter DW, Moradian GP, Castaneda-Zuniga WR, Letourneau JG. Transplant renal artery stenosis: evaluation with duplex sonography. Radiology 1989;172: 1027-1030

31. Taylor KJ, Morse SS, Rigsby CM, Bia M, Schiff M. Vascular complications in renal allografts: detection with duplex Doppler US. Radiology 1987;162:31-38

32. de Morais RH, Muglia VF, Mamere AE, et al. Duplex Doppler sonography of transplant renal artery stenosis. J Clin Ultrasound 2003;31:135-141

33. Kelekis NL, Semelka RC, Worawattanakul S, Molina PL, Mauro MA. Magnetic resonance imaging of the abdominal aorta and iliac vessels using combined 3-D gadoliniumenhanced MRA and gadolinium-enhanced fat-suppressed spoiled gradient echo sequences. Magn Reson Imaging 1999; 17:641-651

34. Huber A, Heuck A, Scheidler J, et al. Contrast-enhanced MR angiography in patients after kidney transplantation. Eur Radiol 2001;11:2488-2495

35. Chan YL, Leung CB, Yu SC, Yeung DK, Li PK. Comparison of non-breath-hold high resolution gadolinium-enhanced MRA with digital subtraction angiography in the evaluation on allograft renal artery stenosis. Clin Radiol 2001;56:127-132

36. Ferreiros J, Mendez R, Jorquera M, et al. Using gadoliniumenhanced three-dimensional MR angiography to assess arterial inflow stenosis after kidney transplantation. AJR Am J Roentgenol 1999;172:751-757

37. Luk SH, Chan JH, Kwan TH, Tsui WC, Cheung YK, Yuen MK. Breath-hold 3D gadolinium-enhanced subtraction MRA in the detection of transplant renal artery stenosis. Clin Radiol 1999;54:651-654

38. Barrett BJ, Carlisle EJ. Metaanalysis of the relative nephrotoxicity of high- and low-osmolality iodinated contrast media. Radiology 1993;188:171-178

39. Chalmers N, Jackson RW. Comparison of iodixanol and iohexol in renal impairment. Br J Radiol 1999;72:701-703

40. Davidson CJ, Laskey WK, Hermiller JB, et al. Randomized trial of contrast media utilization in high-risk PTCA: the COURT trial. Circulation 2000;101:2172-2177

41. Gossmann J, Liermann D, Scheuermann EH, Lenz T. Curable hypertensive renal failure due to iliac artery stenosis 
in a kidney transplant recipient. Nephrol Dial Transplant 1997;12:596-598

42. Butterworth PC, Bolia A, Nicholson ML. Recurrent pulmonary oedema caused by iliac artery stenosis in a renal transplant recipient. Nephron 1998;79:119-120

43. Thomsen HS, Dorph S, Mygind T, Holm HH, Munck O, Damgaard-Pedersen K. The transplanted kidney. Diagnostic and interventional radiology. Acta Radiol Diagn (Stockh) 1985;26:353-367

44. Gedroyc WM, Reidy JF, Saxton HM. Arteriography of renal transplantation. Clin Radiol 1987;38:239-243

45. Picus D, Neeley JP, McClennan BL, Weyman PJ, Heiken JP. Intraarterial digital subtraction angiography of renal transplants. AJR Am J Roentgenol 1985;145:93-96

46. Seymour HR, Matson MB, Belli AM, Morgan R, Kyriou J, Patel U. Rotational digital subtraction angiography of the renal arteries: technique and evaluation in the study of native and transplant renal arteries. Br J Radiol 2001;74:134141

47. Hagen G, Wadstrom J, Magnusson A. 3D rotational angiography of transplanted kidneys. Acta Radiol 2003;44: 193-198

48. Burgener FA, Schabel SI. The radiographic size of renal transplants. Radiology 1975;117:547-550

49. Fletcher EW, Lecky JW. The radiological size of renal transplants—a retrospective study. Br J Radiol 1969;42:892898

50. Waybill MM, Waybill PN. Contrast media-induced nephrotoxicity: identification of patients at risk and algorithms for prevention. J Vasc Interv Radiol 2001;12:3-9

51. Briguori C, Tavano D, Colombo A. Contrast agentassociated nephrotoxicity. Prog Cardiovasc Dis 2003;45: 493-503

52. Moresco KP, Patel NH, Namyslowski Y, Shah H, Johnson MS, Trerotola SO. Carbon dioxide angiography of the transplanted kidney: technical considerations and imaging findings. AJR Am J Roentgenol 1998;171:1271-1276

53. Kerns SR, Hawkins IF Jr, Sabatelli FW. Current status of carbon dioxide angiography. Radiol Clin North Am 1995; 33:15-29

54. Spinosa DJ, Matsumoto AH, Angle JF, et al. Gadoliniumbased contrast and carbon dioxide angiography to evaluate renal transplants for vascular causes of renal insufficiency and accelerated hypertension. J Vasc Interv Radiol 1998;9:909916

55. Hawkins IF Jr, Wilcox CS, Kerns SR, Sabatelli FW. $\mathrm{CO}_{2}$ digital angiography: a safer contrast agent for renal vascular imaging? Am J Kidney Dis 1994;24:685-694

56. Harward TR, Smith S, Hawkins IF, Seeger JM. Follow-up evaluation after renal artery bypass surgery with use of carbon dioxide arteriography and color-flow duplex scanning. J Vasc Surg 1993;18:23-30

57. Caridi JG, Hawkins IF Jr. $\mathrm{CO}_{2}$ digital subtraction angiography: potential complications and their prevention. J Vasc Interv Radiol 1997;8:383-391

58. Weissleder R. Can gadolinium be safely given in renal failure? AJR Am J Roentgenol 1996;167:278-279

59. Prince MR, Arnoldus C, Frisoli JK. Nephrotoxicity of highdose gadolinium compared with iodinated contrast. J Magn Reson Imaging 1996;6:162-166

60. Niendorf HP, Haustein J, Cornelius I, Alhassan A, Clauss W. Safety of gadolinium-DTPA: extended clinical experience. Magn Reson Med 1991;22:222-228
61. Gemery J, Idelson B, Reid S, et al. Acute renal failure after arteriography with a gadolinium-based contrast agent. AJR Am J Roentgenol 1998;171:1277-1278

62. Bakris GL, Lass NA, Glock D. Renal hemodynamics in radiocontrast medium-induced renal dysfunction: a role for dopamine-1 receptors. Kidney Int 1999;56:206-210

63. Tepel M, van der Giet M, Schwarzfeld C, Laufer U, Liermann D, Zidek W. Prevention of radiographic-contrast-agent-induced reductions in renal function by acetylcysteine. N Engl J Med 2000;343:180-184

64. Briguori C, Manganelli F, Scarpato P, et al. Acetylcysteine and contrast agent-associated nephrotoxicity. J Am Coll Cardiol 2002;40:298-303

65. Roberts JP, Ascher NL, Fryd DS, et al. Transplant renal artery stenosis. Transplantation 1989;48:580-583

66. Hohnke C, Abendroth D, Schleibner S, Land W. Vascular complications in 1,200 kidney transplantations. Transplant Proc 1987;19:3691-3692

67. Benoit G, Moukarzel M, Hiesse C, Verdelli G, Charpentier B, Fries D. Transplant renal artery stenosis: experience and comparative results between surgery and angioplasty. Transpl Int 1990;3:137-140

68. Gray D. Graft renal artery stenosis in the transplanted kidney. Transpl Rev 1994;8:15-21

69. Sniderman KW, Sprayregen S, Sos TA, et al. Percutaneous transluminal dilation in renal transplant arterial stenosis. Transplantation 1980;30:440-444

70. Grossman RA, Dafoe DC, Shoenfeld RB, et al. Percutaneous transluminal angioplasty treatment of renal transplant artery stenosis. Transplantation 1982;34:339-343

71. Becker BN, Odorico JS, Becker YT, et al. Peripheral vascular disease and renal transplant artery stenosis: a reappraisal of transplant renovascular disease. Clin Transplant 1999;13: 349-355

72. Braun WE. Long-term complications of renal transplantation. Kidney Int 1990;37:1363-1378

73. Raine AE, Carter R, Mann JI, Morris PJ. Adverse effect of cyclosporin on plasma cholesterol in renal transplant recipients. Nephrol Dial Transplant 1988;3:458-463

74. Weigele JB. Iliac artery stenosis causing renal allograftmediated hypertension: angiographic diagnosis and treatment. AJR Am J Roentgenol 1991;157:513-515

75. Raynaud A, Bedrossian J, Remy P, Brisset JM, Angel CY, Gaux JC. Percutaneous transluminal angioplasty of renal transplant arterial stenoses. AJR Am J Roentgenol 1986; 146:853-857

76. Greenstein SM, Verstandig A, McLean GK, et al. Percutaneous transluminal angioplasty. The procedure of choice in the hypertensive renal allograft recipient with renal artery stenosis. Transplantation 1987;43:29-32

77. Patel NH, Jindal RM, Wilkin T, et al. Renal arterial stenosis in renal allografts: retrospective study of predisposing factors and outcome after percutaneous transluminal angioplasty. Radiology 2001;219:663-667

78. Halimi JM, Al-Najjar A, Buchler M, et al. Transplant renal artery stenosis: potential role of ischemia/reperfusion injury and long-term outcome following angioplasty. J Urol 1999; 161:28-32

79. Clements R, Evans C, Salaman JR. Percutaneous transluminal angioplasty of renal transplant artery stenosis. Clin Radiol 1987;38:235-237

80. Chandrasoma P, Aberle AM. Anastomotic line renal artery stenosis after transplantation. J Urol 1986;135:1159-1162 
81. Matalon TA, Thompson MJ, Patel SK, Brunner MC, Merkel FK, Jensik SC. Percutaneous transluminal angioplasty for transplant renal artery stenosis. J Vasc Interv Radiol 1992;3:55-58

82. Bertoni E, Zanazzi M, Rosat A, et al. Efficacy and safety of Palmaz stent insertion in the treatment of renal artery stenosis in kidney transplantation. Transpl Int 2000;13(suppl 1): S425-S430

83. Newman-Sanders AP, Gedroyc WG, al-Kutoubi MA, Koo $\mathrm{C}$, Taube D. The use of expandable metal stents in transplant renal artery stenosis. Clin Radiol 1995;50:245-250
84. Sierre SD, Raynaud AC, Carreres T, Sapoval MR, Beyssen BM, Gaux JC. Treatment of recurrent transplant renal artery stenosis with metallic stents. J Vasc Interv Radiol 1998;9:639644

85. Martin LG, Rundback JH, Sacks D, et al. Quality improvement guidelines for angiography, angioplasty, and stent placement in the diagnosis and treatment of renal artery stenosis in adults. J Vasc Interv Radiol 2002;13:10691083 